\title{
Doctors' drinking habits and consumption of alcohol
}

\author{
Juhani Juntunen, Sisko Asp, Martti Olkinuora, Markku Äärimaa, Leo Strid, Kyllikki Kauttu
}

\begin{abstract}
Alcohol consumption and drinking habits among Finnish doctors were studied as part of a survey of stress and burnout. A questionnaire containing 99 questions or groups of questions was sent to all 3496 practising doctors aged under 66 randomly selected from the registry of the Finnish Medical Association. Altogether 2671 doctors (76\%) responded; this sample was representative of the Finnish medical profession. The average weekly consumption of alcohol during the past year and various aspects of drinking behaviour were assessed, and the presence or absence of symptoms and diseases often encountered among heavy drinkers and addicts was determined. The data were analysed separately for men and women, for those aged $\leqslant \mathbf{4 0}$ and $>40$, and for the men with high and low alcohol consumption and with high and low scores on the index of drinking habits. Selected variables related to work, stress, and coping were correlated with
\end{abstract} alcohol consumption and drinking behaviour.

The median consumption of alcohol among male doctors was $4876 \mathrm{~g}$ (6.2 litres) and among female doctors $2226 \mathrm{~g}$ ( 2.8 litres) of absolute alcohol per person per year and was higher in those aged over 40 . Beer was most commonly drunk by men and wine by women. Increased alcohol consumption was associated with older age, disappointment with career, heavy smoking, use of benzodiazepines, stress and burnout symptoms, suicidal thoughts, general dissatisfaction, and diseases related to alcohol. Drinking habits were heavier among doctors working in community health centres, those taking long sick leaves, younger doctors disappointed with their careers or the atmosphere at work, and older doctors immersed in their work.

Alcohol consumption among doctors seems to be higher than that of the general population in Finland, and heavy drinking seems to be associated with stress and burnout.

\section{Introduction}

Consumption of alcohol by members of the medical profession has attracted much attention from researchers in the past two decades. ${ }^{1-13}$ Most studies have focused on the variable aspects of drinking behaviour and provide conflicting data about the actual consumption of alcohol by doctors. Mortality statistics of some countries show that diseases related to alcohol, such as cirrhosis of the liver, are common among medical doctors,${ }^{13}$ as are suicide,${ }^{14}$ drug abuse,,${ }^{115}$ and cardiovascular disease. ${ }^{1617}$ Case reports of alcoholic doctors may have given doctors in general the reputation of being exceptionally heavy drinkers. This study was based on a questionnaire designed to obtain data about drinking habits and associated factors among doctors currently practising in Finland and was part of a more comprehensive study on stress and burnout in Finnish doctors. ${ }^{18}$

Association, SF-0018

Helsinki

Markku Äärimaa, MD, secretary general

Leo Strid, MD, president

Kyllikki Kauttu, BA, editor,

Finnish Medical foumal

Correspondence to:

Dr Juntunen.
The Finnish Medical Association's registry listed 11386 doctors in 1986. Of these, 10479 were permanently resident in Finland, under 66 years old not receiving a disability pension, and fully authorised. Every third doctor was randomly selected from this group, giving 3496 subjects. A questionnaire containing 99 questions or groups of questions was sent with a letter describing the aims of the study to all doctors selected to participate. Total anonymity was assured, and the questionnaires did not contain any questions or codes that could possibly identify the responder.

Average weekly consumption of alcohol during the past year was assessed separately for beer, wine, and spirits. Each was scaled according to the number of bottles or glasses consumed, and these scales were transformed into grams of absolute alcohol. The amount of alcohol consumed does not, however, give a full picture of drinking behaviour: the manner in which alcohol is used is another important aspect. Scores for 12 questions measuring various aspects of drinking behaviour were summed for each subject to obtain an index of drinking habits (table I). The

TABLE I-Questions constituting the index of drinking habits

\begin{tabular}{|c|c|}
\hline & $\begin{array}{c}\text { Score } \\
(\text { maximum }=24)\end{array}$ \\
\hline Do you ever use alcohol to relieve burnout? & 0 or 1 \\
\hline $\begin{array}{l}\text { Have you increased your alcohol consumption during } \\
\text { the past few years? } \\
\text { Have you ever felt that you drink too much? }\end{array}$ & $\begin{array}{l}0 \text { or } 2 \\
0 \text { or } 1\end{array}$ \\
\hline $\begin{array}{l}\text { Has your spouse/a friend } / \text { a relative ever told you that } \\
\text { you drink too much? } \\
(0=\text { no, } 1=\text { sometimes, } 2=\text { often })\end{array}$ & $0-2$ \\
\hline $\begin{array}{l}\text { Have you ever thought of stopping drinking altogether? } \\
\text { Have you been drunk at any time during the past year? } \\
(0=\leqslant 3 \text { times, } 1=4-6 \text { times, } 2=\geqslant 7 \text { times })\end{array}$ & $\begin{array}{c}0 \text { or } 1 \\
0-2\end{array}$ \\
\hline $\begin{array}{l}\text { Have you been heavily drunk at any time during the past } \\
\text { year? } \\
(0=\text { no or once, } 1=2-3 \text { times, } 2=\geqslant 4 \text { times })\end{array}$ & $0-2$ \\
\hline $\begin{array}{l}\text { Have you ever had amnesia when drinking? } \\
\text { Have you had a hangover during the past year? } \\
(0=\leqslant 2 \text { times, } 1=3-5 \text { times, } 2=\geqslant 6 \text { times })\end{array}$ & $\begin{array}{c}0 \text { or } 2 \\
0-2\end{array}$ \\
\hline $\begin{array}{l}\text { Have you used alcohol to relieve a hangover during the } \\
\text { past year? } \\
(0=\text { no, } 1=1-2 \text { times, } 2=3-5 \text { times, } 3=\geqslant 6 \text { times })\end{array}$ & $0-3$ \\
\hline $\begin{array}{l}\text { Have you ever had alcohol withdrawal symptoms other } \\
\text { than a hangover? }\end{array}$ & 0 or 3 \\
\hline $\begin{array}{l}\text { Have you ever remained drunk for two or more } \\
\text { consecutive days without being sober? } \\
(0=\text { no, } 2=\text { occasionally, } 3=\text { often })\end{array}$ & $0-3$ \\
\hline
\end{tabular}

presence or absence of symptoms and diseases often found in heavy drinkers and alcoholics-namely, gastritis, tremor, depression, anxiety, insomnia, headache, irritability, nausea, and hypertensionwere scored 1 and 0 , respectively; abnormal liver function values and use of $\beta$ blockers for anxiety or tremor were scored 0 when absent and 3 when present. For the larger study on stress and burnout items were included to show characteristics of addictive behaviour in general, and the answers to questions on stress and burnout were summed into the three categories exhaustion, emotional detachment, and personal accomplishment (as in the Maslach burnout inventory ${ }^{19}$ ); these findings have been reported elsewhere. ${ }^{18}$

The analysis concentrated on the heavy drinkersthat is, doctors in the upper quarter of the distribution of alcohol consumption. The variables were dichotomised into weekly consumption of alcohol of $<200 \mathrm{~g}$ or $\geqslant 200 \mathrm{~g}$ of absolute alcohol and index of drinking habit of $<6$ or $\geqslant 6$. The data were analysed separately for men and women and for those aged 40 or under and those over 40. Variables were correlated with alcohol consumption and drinking habits by fourfold tables and the Mantel-Haenszel procedure. The 
consumption of alcohol among women doctors was low, so only that of the men was analysed in greater detail.

\section{Results}

Altogether 2671 (76\%) doctors responded (table II).

TABLE II -Study population according to sex, age, and specialisation

\begin{tabular}{lccc}
\hline & $\begin{array}{c}\text { Men } \\
(\mathrm{n}=1600)\end{array}$ & $\begin{array}{c}\text { Women } \\
(\mathrm{n}=1069)\end{array}$ & $\begin{array}{c}\text { Total } \\
\left(\mathrm{n}=2669^{\star}\right)\end{array}$ \\
\hline Age (years): & & & \\
$\quad \leqslant 30$ & 207 & 261 & 468 \\
$31-40$ & 721 & 523 & 1244 \\
$41-50$ & 426 & 207 & 633 \\
$51-65$ & 239 & 77 & 316 \\
$\quad$ Unknown & 7 & 1 & 8 \\
Specialisation: & & & \\
$\quad$ General practitioners & 636 & 661 & 1297 \\
Specialists & 964 & 408 & 1372 \\
\hline
\end{tabular}

*In two additional cases sex was unknown.

Some doctors did not respond to all questions. The final sample was considered to be representative of the Finnish medical profession in terms of age, sex, specialisation, and type of employment (table III). The mean age was the same in both groups, being 40 years for men and 37 for women.

TABLE III-Responders to questionnaire as a representative sample of all Finnish doctors working in Finland. Values are percentages (and numbers ${ }^{\star}$ )

\begin{tabular}{lcc}
\hline & $\begin{array}{c}\text { All doctors } \\
(\mathrm{n}=10479)\end{array}$ & $\begin{array}{c}\text { Respondents } \\
(\mathrm{n}=2671)\end{array}$ \\
\hline $\begin{array}{l}\text { Sex: } \\
\text { Male }\end{array}$ & $62(6497)$ & $60(1602)$ \\
$\quad$ Female & $38(3982)$ & $40(1068)$ \\
Proportion of specialists: & $58(6078)$ & $59(1576)$ \\
$\quad$ Males & $35(3668)$ & $37(988)$ \\
$\quad$ Women & & \\
Distribution according to post: & & \\
$\quad$ Men: & $52(5449)$ & $55(1469)$ \\
$\quad$ Hospital & $23(2410)$ & $21(561)$ \\
$\quad$ Municipal health centre & $25(2620)$ & $24(641)$ \\
$\quad$ Other & & \\
$\quad$ Women: & $42(4401)$ & $46(1229)$ \\
$\quad$ Hospital & $36(3772)$ & $33(881)$ \\
$\quad$ Municipal health centre & $22(2305)$ & $21(561)$ \\
$\quad$ Other & & \\
\hline
\end{tabular}

${ }^{\star}$ In several cases sex and specialisation were unknown.

Table IV shows the total consumption of alcohol by Finnish doctors. Men consumed a median of $4876 \mathrm{~g}$ (6.2 litres) and women $2226 \mathrm{~g}$ ( 2.8 litres) of absolute alcohol a year. Consumption was slightly higher among those aged over 40 than those aged 40 and under $(5402 \mathrm{~g}$ and $4611 \mathrm{~g}$ for men, $2491 \mathrm{~g}$ and $2120 \mathrm{~g}$ for women, respectively). Eighty one (10\%) women and 57

TABLE IV-Consumption of alcohol by doctors in Finland. Quantitites are given as grams of absolute alcohol consumed weekly

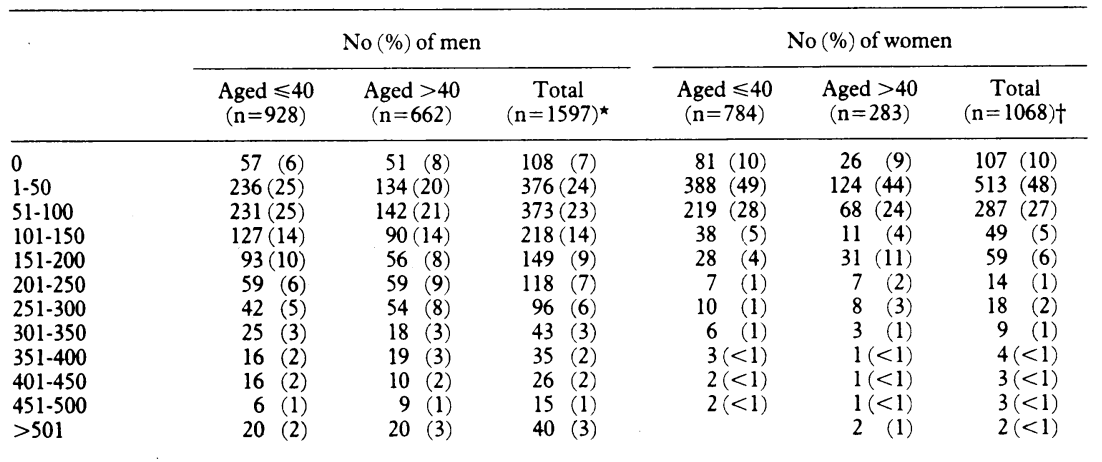

^Ages of seven men were unknown.

tAge of one woman was unknown.
(6\%) men aged 40 or under and $26(9 \%)$ women and 51 $(8 \%)$ men aged over 40 were teetotallers. Altogether $23 \%(368)$ of the men and $15 \%$ (160) of the women accounted for half the alcohol consumed; $24 \%$ (373) of the men and $3 \%(55)$ of the women consumed more than $200 \mathrm{~g}$ of absolute alcohol a week; and $4 \%$ (64) of the men consumed more than 30 litres of absolute alcohol a year $(>450 \mathrm{~g} /$ week).

Table $\mathrm{V}$ shows the average weekly consumption of beer, wine, and spirits. The consumption of spirits was highest $(31 \%)$ among men aged over 40 . Beer was the most common source of alcohol among men, accounting for $42 \%$ of their total consumption. Women took their alcohol mostly as wine-40\% among younger women and 52\% among older women, but beer was almost as popular among the younger women.

Table VI shows the proportions of heavy drinkers $(\geqslant 200 \mathrm{~g} /$ week) in major specialties. The proportion was somewhat higher among specialists than among non-specialists and was highest among radiologists, specialists in internal medicine, and general practitioners. A higher proportion of heavy drinkers was found among doctors working in municipal health centres and occupational health care units than in other posts. No great differences were found between the other groups. Heavy drinking was associated with heavy smoking, career disappointment, apparent meaninglessness of the work, use of benzodiazepines (33 (9\%)), exhaustion, and dissatisfaction with life. On the other hand, family matters, professional ability, emotional dependence on work, personal accomplishment, and general atmosphere at work were not related to higher consumption of alcohol or to diseases related to alcohol.

When the men were divided into heavy drinkers and social drinkers (scores on drinking habits index of $\geqslant 6$ and $<6$, respectively) no major differences were found between groups of specialists (table VI). Older general practitioners had slightly heavier drinking habits than younger ones. Drinking among specialists was more moderate than that among general practitioners. A score on the drinking habit index of 6 or more was significantly associated with disappointment with the career, heavy smoking, use of benzodiazepines, exhaustion, emotional detachment, and apparent meaninglessness of the work (all at $\mathrm{p}<0.001$ ) and with unpleasant atmosphere at work and long sick leaves $(p<0.05)$. A negative correlation was found between drinking habits and personal accomplishment $(p<0.001)$. Home and family matters and general satisfaction with life were also significantly related to drinking behaviour $(\mathrm{p}<0.001)$.

A clear correlation between intake of alcohol and diseases related to alcohol was found in men whose score on the drinking habit index was $\geqslant 6$ and whose alcohol consumption was $\geqslant 200 \mathrm{~g}$ of absolute alcohol a week compared with the moderate drinkers $(z=9 \cdot 50$, $\mathrm{p}<0.001$, test for trend). Table VII gives the breakdown according to the index of diseases related to alcohol in four categories combining alcohol consumption and drinking behaviour.

Table VIII groups the men by their main position according to the four categories combining alcohol consumption and drinking behaviour. Assistant hospital doctors consumed considerably less alcohol than other doctors. Doctors working in municipal health centres and in occupational health consumed more alcohol and drank more heavily than other doctors. Private practitioners consumed more alcohol than others, but their drinking behaviour was more moderate. When the extreme groups were compared on selected issues related to work, stress, and coping, alcohol consumption and drinking behaviour correlated with several other factors (table IX). Positive 
correlations were found with smoking, use of benzodiazepines, life changes, and suicidal thoughts; negative correlations were found with satisfaction with career and general satisfaction with life. No correlations were found with impermanence of employment, atmosphere at work, emotional dependence on work, physical activity, and sick leave.

\section{Discussion}

Reports from different countries strongly suggest that the medical profession is one of those most at risk of alcoholism. ${ }^{12}$ Alcoholism is defined as a state

TABLE V-Mean intake of alcohol per week ( $\mathrm{g}$ absolute alcohol). Numbers in parentheses are percentages of total intake for age group

\begin{tabular}{|c|c|c|c|c|c|}
\hline & Beer & Wine & Spirits & Tot & \\
\hline Men & $59(42)$ & $40(29)$ & $40(29)$ & & $139(100)$ \\
\hline$\leqslant 40$ years & $59(45)$ & $36(27)$ & $36(27)$ & $131(100)$ & \\
\hline$>40$ years & $58(38)$ & $46(30)$ & $47(31)$ & $151(100)$ & \\
\hline Women & $22(34)$ & $29(44)$ & $14(22)$ & & $65(100)$ \\
\hline$\leqslant 40$ years & $22(37)$ & $24(40)$ & $14(23)$ & $60(100)$ & \\
\hline$>40$ years & $22(28)$ & $42(52)$ & $16(20)$ & $80(100)$ & \\
\hline
\end{tabular}

characterised by a physical dependence on alcohol ${ }^{20}$; it is an extreme condition found in heavy drinkers. ${ }^{13}$ Our study focused on the overall consumption of alcohol in a working population of medical doctors and classifications with respect to drinking should be interpreted accordingly. Our findings suggest that on the whole Finnish doctors consume a fairly large amount of alcohol. Drinking habits and consumption of alcohol seemed to be related to age, sex, and some occupational factors. The sample was representative of the whole profession and sufficiently large for statistical inferences to be made. Owing to the anonymity of the questionnaire we could not tell what age, sex, or category of doctors failed to respond, but in view of the similar percentages of responders in all groups non-responders are unlikely to have introduced any bias to the results.

The problems inherent in questionnaire studies are well known, and results should be interpreted with caution. For example, estimates of alcohol consumption are crude measures, and responders may underestimate their intake. Questions may also be interpreted differently by different responders. Direct comparisons of the present results with those of other

TABLE VI-Proportions of male doctors in different specialties with high alcohol consumption ( $\geqslant 200 \mathrm{~g} /$ week) and index of drinking habit $\geqslant 6$

\begin{tabular}{|c|c|c|c|c|c|c|c|c|}
\hline & \multicolumn{4}{|c|}{ Alcohol consumption $\geqslant 200 \mathrm{~g} /$ week } & \multicolumn{4}{|c|}{ Drinking habit index $\geqslant 6$} \\
\hline & \multirow[b]{2}{*}{ No responding to question } & \multicolumn{2}{|c|}{ No $(\%)$ drinking $\geqslant 200 \mathrm{~g} /$ week } & \multirow{2}{*}{$\begin{array}{c}\text { Total \% } \\
\text { drinking } \\
\geqslant 200 \mathrm{~g} / \text { week }^{\star}\end{array}$} & \multirow[b]{2}{*}{ No responding to question } & \multicolumn{2}{|c|}{ No $(\%)$ with index $\geqslant 6$} & \multirow{2}{*}{$\begin{array}{c}\text { Total \% } \\
\text { with } \\
\text { index } \geqslant 6^{\star}\end{array}$} \\
\hline & & Aged $\leqslant 40$ & Aged $>40$ & & & Aged $\leqslant 40$ & Aged $>40$ & \\
\hline All specialties & 923 & $79(23)$ & $167(29)$ & 25 & 839 & $80(25)$ & $184(22)$ & 24 \\
\hline Anaesthesiology & 44 & $5(24)$ & $4(17)$ & 21 & 37 & $4(24)$ & $1(5)$ & $16^{27}$ \\
\hline Internal medicine & 130 & $9(21)$ & $34(39) \dagger$ & 28 & 123 & $8(21)$ & $20(24)$ & 22 \\
\hline Surgery, neurosurgery & 136 & $15(26)$ & $19(24)$ & 25 & 119 & $12(24)$ & $18(26)$ & 25 \\
\hline Gynaecology and obstetrics & 65 & $4(17)$ & $11(26)$ & 21 & 62 & $6(27)$ & $6(15)$ & 22 \\
\hline Paediatrics & 35 & $3(27)$ & $5(21)$ & 25 & 30 & $3(27)$ & $1(5)$ & 18 \\
\hline Psychiatry & 66 & $4(19)$ & $15(33)$ & 25 & 61 & $1(5) \dagger$ & $11(28)$ & 14 \\
\hline Otorhinolaryngology & 39 & $2(13)$ & $6(26)$ & 18 & 34 & $5(33)$ & $6(32)$ & 33 \\
\hline Ophthalmology & 25 & & $3(18)$ & 7 & 22 & & $2(14)$ & 6 \\
\hline Primary health care & 122 & $15(25)$ & $17(27)$ & 26 & 115 & $12(21)$ & $18(31)$ & 25 \\
\hline Radiology & 57 & $4(31)$ & $20(45) t$ & $37 t$ & 50 & $7(54) t$ & $10(27)$ & 43 \\
\hline Other & 204 & $18(24)$ & $33(26)$ & 25 & 186 & $22(33)$ & $21(18)$ & 26 \\
\hline General practice & 631 & $102(18)$ & $14(22)$ & $19 \ddagger$ & 569 & $144(28)$ & $19(34)$ & 31 \\
\hline
\end{tabular}

* Standardised to age distribution of all male doctors.

$t p<0.05$, Mantel-Haenszel test for each specialty against other specialties.

$\neq \mathrm{p}<0.05$, Mantel-Haenszel test for general practice against all specialties.

TABLE VII - Number (percentage) of male doctors with diseases related to alcohol grouped by high and low alcohol consumption and score on drinking habit index

\begin{tabular}{lrrrr}
\hline \multirow{2}{*}{$\begin{array}{c}\text { Score on } \\
\text { index of } \\
\text { diseases related } \\
\text { to alcohol }\end{array}$} & \multicolumn{4}{c}{ Alcohol consumption and score on drinking habit index } \\
\cline { 2 - 6 } & $\begin{array}{r}<200 \mathrm{~g} \\
\text { and }<6\end{array}$ & $\begin{array}{r}<200 \mathrm{~g} \\
\text { and } \geqslant 6\end{array}$ & $\begin{array}{r}\geqslant 200 \mathrm{~g} \\
\text { and }<6\end{array}$ & $\begin{array}{r}\geqslant 200 \mathrm{~g} \\
\text { and } \geqslant 6\end{array}$ \\
\hline 0 & $596(69)$ & $68(46)$ & $93(67)$ & $85(45)$ \\
1 & $150(17)$ & $34(23)$ & $25(18)$ & $42(22)$ \\
2 & $53(6)$ & $20(13)$ & $6(4)$ & $18(10)$ \\
3 & $33(4)$ & $16(11)$ & $8(6)$ & $21(11)$ \\
4 & $17(2)$ & $7(5)$ & $3(2)$ & $11(6)$ \\
$\geqslant 5$ & $12(1)$ & $4(3)$ & $3(2)$ & $11(6)$ \\
\hline Total & 861 & 149 & 138 & 188 \\
\end{tabular}

TABLE VIII -Numbers (percentages ${ }^{\star}$ ) of male doctors in different types of work grouped by high and low alcohol consumption and score on drinking habit index studies on other occupations are not possible because of differences in the design of the questionnaires, but comparisons between different groups within this study can, of course, be made.

The distribution of alcoholic beverages in Finland is controlled by the state alcohol monopoly. Its statistics show that the mean alcohol consumption of each person, children included, in Finland was 6.9 litres of absolute alcohol in 1986, which is fairly low in comparison with other countries. Drinking habits in Finland differ somewhat from those in wine drinking countries. In Finland there is a moral ambivalence towards drinking and heavy drinking leading to drunkenness. Drunkenness is responsible for most

\begin{tabular}{|c|c|c|c|c|c|}
\hline \multirow[b]{2}{*}{ Main post } & \multirow{2}{*}{$\begin{array}{l}\text { No responding } \\
\text { to question }\end{array}$} & \multicolumn{4}{|c|}{ Alcohol consumption and score on drinking habit index } \\
\hline & & $<200 \mathrm{~g}$ and $<6$ & $<200 \mathrm{~g}$ and $\geqslant 6$ & $\geqslant 200 \mathrm{~g}$ and $<6$ & $\geqslant 200 \mathrm{~g}$ and $\geqslant 6$ \\
\hline \multicolumn{6}{|l|}{ Hospitals: } \\
\hline Physicians in chief & 359 & $223(66)$ & $28(6)$ & $53(12)$ & $55(15)$ \\
\hline Ward physicians and specialists & 362 & $226(62)$ & $41(11)$ & $43(12)$ & $52(15)$ \\
\hline Assistant physicians & 191 & $136(72)$ & $29(14)$ & $8(4)$ & $18(10)$ \\
\hline Doctors working in health centres and occupational health & 320 & $198(59)$ & $49(15)$ & $23(9)$ & $50(17)$ \\
\hline Private practice & 60 & $37(62)$ & $3(6)$ & $11(18)$ & $9(15)$ \\
\hline Other (research workers, professors, office workers, managers) & 143 & $99(69)$ & $15(11)$ & $11(8)$ & $18(13)$ \\
\hline Total & 1435 & $919(64)$ & $165(12)$ & $149(10)$ & $202(14)$ \\
\hline
\end{tabular}

$\star$ Standardised to age distribution of all male doctors. 
TABLE IX - Numbers (percentages ${ }^{\star}$ ) of doctors in groups with extremes of alcohol consumption and score on drinking habit index $(<200 \mathrm{~g}$ and $<6 v \geqslant 200 \mathrm{~g}$ and $\geqslant 6)$ giving positive answers to questions related to work, stress, and coping

\begin{tabular}{|c|c|c|c|c|}
\hline & \multirow{2}{*}{$\begin{array}{l}\text { No responding } \\
\text { to question }\end{array}$} & \multicolumn{2}{|c|}{$\begin{array}{l}\text { Alcohol consumption and score } \\
\text { on drinking habit index }\end{array}$} & \multirow[b]{2}{*}{ p Value } \\
\hline & & $<200 \mathrm{~g}$ and $<6$ & $\geqslant 200 \mathrm{~g}$ and $\geqslant 6$ & \\
\hline Post not permanent & 1115 & $286(30)$ & $55(27)$ & \\
\hline Dissatisfied or very dissatisfied with career & 1117 & $78(8)$ & $31(15)$ & $<0.01$ \\
\hline Working atmosphere unsatisfactory & 1118 & $84(9)$ & $26(13)$ & \\
\hline Seldom or never able to withdraw from work & 1118 & $108(12)$ & $32(16)$ & \\
\hline Exercise $\leqslant 2$ hours a week & 1119 & $334(64)$ & $74(63)$ & \\
\hline Smoking $\geqslant 11$ cigarettes/day & 1108 & 40 (4) & $42(21)$ & $<0.001$ \\
\hline \multicolumn{5}{|l|}{ Benzodiazepines taken frequently or } \\
\hline continuously & 1123 & 28 (3) & $29(14)$ & $<0.001$ \\
\hline Illnesses requiring sick leave & 1123 & $251(27)$ & $61(30)$ & \\
\hline Changes within family or close relationships & 1123 & $144(16)$ & $49(24)$ & $<0 \cdot 01$ \\
\hline Somewhat or very dissatisfied with life & 1119 & $71(8)$ & $39(19)$ & $<0.001$ \\
\hline Suicidal thoughts, plans, or attempts & 1121 & $163(18)$ & $63(31)$ & $<0.001$ \\
\hline
\end{tabular}

problems related to alcohol in Finland, and most of the alcohol is consumed by only a minority of the population. Increasing concern about the effects of alcohol on health has led to nationwide campaigns against heavy drinking and to changes in the regulatory policies of the state alcohol monopoly. A questionnaire study carried out among the population aged 15-69 showed that the mean consumption of absolute alcohol a year was 1.3 litres among women and 4.5 litres among men and that $27 \%$ of women and $12 \%$ of men were teetotallers. Although in the present study the questions on drinking habits were formulated differently and covered a more restricted population, it is clear that, as a group, Finnish doctors consumed more alcohol than the general population. This difference is not accounted for by the differences in questions on alcohol consumption between this and other studies or by the effect of non-responders.

We used indexes and dichotomised variables in our statistical analysis to sharpen the detection of possible effects of alcohol consumption that might be diluted in the total sample. Though no correlation was found between alcohol consumption and symptoms and signs usually associated with somatic diseases related to alcohol, when high alcohol consumption was considered together with habits of heavy drinking a clear correlation was found between increased alcohol consumption and somatic symptoms and signs. Thus consumption of alcohol among Finnish doctors is high enough to cause adverse effects on health in many of them.

An interesting difference between male and female doctors was seen in the type of alcohol they used. Women drank mostly wine, whereas beer was the most popular drink among men. Younger men seemed to favour beer more than did older men, who drank beer, wine, and spirits in equal proportions.

Disappointment with the career and the apparent meaninglessness of the work were clearly related to increased consumption of alcohol, whereas other factors related to occupation, such as emotional dependence on work and the atmosphere at work, seemed not to affect drinking behaviour. On the other hand, many of the non-occupational factorsdissatisfaction with life, family matters, smoking, use of tranquillisers, addictive behaviour in general, stress, burnout, and suicidal thoughts-were clearly associated with increased consumption of alcohol.
Senior and assistant hospital doctors consumed less alcohol and doctors working in health centres and occupational health consumed more alcohol than other groups. Despite the fairly high consumption of alcohol among certain specialists their general drinking behaviour was not appreciably different from that of other groups.

Many of the above correlations are obvious and could be predicted from the results of other studies on drinking behaviour. A causal relation is, however, more difficult to pinpoint. The symptoms and signs frequently encountered among heavy drinkers are non-specific and are caused by a multitude of socioeconomic factors. For example, symptoms of stress and burnout were associated with heavy drinking in men; these symptoms were associated with unpleasant working conditions in women with minimal alcohol consumption. It thus seems that occupational factors as such do not play a major part in determining drinking behaviour among doctors.

The results of this study agree with results of studies of drinking problems among groups of doctors in other countries. The association between increased consumption of alcohol and effects on health among a representative sample of doctors engaged in an active career is clear. Indeed, many doctors seem not to benefit from their professional knowledge about the effects of excessive alcohol consumption on health. A change in attitudes towards drinking behaviour among doctors is mandatory to prevent alcoholism among them and, indirectly, among many of their patients.

We thank Mr Markku Viitamäki for his help in selecting material from the registry of the Finnish Medical Association.

1 Glatt MM. Doctors with a drinking problem. Lancet 1975;i:219-20.

2 Edwards G. The alcoholic doctor. Lancet 1975;ii: $1297-8$.

3 Murray RM. Alcoholism amongst male doctors in Scotland. Lancet 1976;ii: 729-31.

4 Murray RM. The medical profession. In: Hore BD, Plant MA, eds. Alcohol problems in employment. London: Croom Helm, 1981:61-76.

5 Bissell L. Alcoholism in physicians. Postgrad Med 1983;74:177-87.

6 O'Hagan J. The alcoholic doctor. NZ Med f 1981;93:192-4.

Rawnsley K. Alcoholic doctors. Alcohol Alcohol 1984;19:257-9.

8 Sclare AB. Alcoholism in doctors. British fournal of Alcohol and Alcoholism 1979;14:181-96

9 Rake MO. Drinking: the doctor's dilemma. British fournal of Alcohol and Alcoholism 1980;15:6-12.

10 Thomas CB, Sanford PB, Shaffer JW. Health of physicians in midlife study of a cohort of former medical students. Johns Hopkins Medical fournal 1980;146:1-10.

11 Wallot H, Lambert J. Characteristics of physician addicts. Am 7 Drug Alcohol Abuse 1984;10:53-62.

12 Lewy R. Alcoholism in house staff physicians: an occupational hazard. $\mathcal{O}$ Occup Med 1986;28:79-8

13 Paton A, Potter JF, Saunders JB. ABC of alcohol: nature of the problem. BrMed F 1981;283:1318-9.

14 Rimpelä AU, Nurminen M, Pulkkinen PO, Rimpelä MK, Valkonen T Mortality of doctors: do doctors benefit from their medical knowledge? Lancet 1987; ; :84-6.

15 Roy A. Suicide in doctors. Psychiatr Clin North Am 1985;8:377-87.

16 Keeve JP. Physicians at risk: some epidemiologic considerations of alcoholism, drug abuse and suicide. $\mathcal{F}$ Occup Med 1984;26:503-8.

17 Goodman LJ. The longevity and mortality of American physicians, 1969-1973. Milbank Mem Fund Q 1975;53:353-75.

18 Olkinuora M, Juntunen J, Asp S, Ärimaa M, Strid L, Kauttu K. Lääkärien stressi, burnout ja suisidaalisuus (Burnout, stress and suicidality among stressi, burnout ja suisidaalisuus (Burnout, stress and

19 Maslach C, Jackson SE. Maslach burnout inventory. Research edition, manual. Palo Alto, California: Consulting Psychologists Press, 1981.

20 American Psychiatric Association. Quick reference to the diagnostic criteria from diagnostic and statistical manual of mental disorders. 3rd ed. Washington, DC: APA, 1980

21 Simpura J, ed. Suomalaisten juomatavat (Finnish drinking habits). Finnish Foundation for Alcohol Studies, 1985. (No 34.)

(Accepted 23 May 1988) 